(2) Open Access Full Text Article

\title{
Approval rating and opinion of outpatients and general practitioners toward generic drugs: a questionnaire-based real-world study
}

This article was published in the following Dove Press journal:

Patient Preference and Adherence

18 August 2017

Number of times this article has been viewed

\section{F Mattioli' \\ G Siri ${ }^{2}$ \\ F Castelli \\ M Puntoni \\ ML Zuccoli' \\ A Stimamiglio 3 \\ A Martelli'}

'Department of Internal Medicine, Clinical Pharmacology and Toxicology Unit, University of Genoa, ${ }^{2}$ Clinical Trial Unit, Scientific Directorate, E.O. Galliera, Genoa, ${ }^{3}$ General Practitioner, Italian National Health System, Local Health Authority: ASL3 Genovese, Genoa, Italy
Correspondence: F Mattioli Clinical Pharmacology and Toxicology Unit, Department of Internal Medicine (Di.M.I.), University of Genoa, Viale Benedetto XV, 2, I-16132 Genoa, Italy Tel +390103538850

Fax +390103538232

Email francesca.mattioli@unige.it
Purpose: Generic drugs use in the Liguria region is higher than the Italian average, but lower than in other European countries. No data exist about real-life prescription and level of awareness of generic drugs. In this study, we analyzed demographic, social, economic and cultural factors that may affect the level of awareness of generic drugs and their effective use.

Methods: We conducted a population survey using a structured questionnaire, administered to a sample of 8 outpatient clinics of general practitioners located in different districts of Genoa (Liguria, Italy). Multivariate logistic modeling was adopted to study the relationship between awareness/use of generic drugs and characteristics of subjects.

Results: Out of 2,000 outpatients surveyed, 95\% were aware of generic drugs: these were mostly females $(\mathrm{OR}=2.2,95 \% \mathrm{CI}: 1.4-3.6),>35$ years old ( $\mathrm{OR}>6.0$ vs $18-35$ years), with a high level of education (OR $>4.4 \mathrm{vs}$ "elementary sch"), living in the west side of the city (OR $=1.9 \mathrm{vs}$ center); of these, only $59 \%$ declared that they effectively use generic drugs. Users were younger (OR $=3.1,18-35$ years vs $>65$ years), with a high level of education (high school/university degree vs no title/elementary/secondary school OR $=1.7$ ), and were aware of the lower cost compared with branded drugs, and were mainly informed by pharmacists and physicians.

Conclusions: Although subjects were substantially aware of the existence of generic drugs, $\sim 40 \%$ still did not use them; doubts about their efficacy seem to be mainly driven by the idea that cheaper drugs lead to lower product quality, in terms of efficacy, safety and tolerability. New education policies on generic drugs are needed.

Keywords: generic drug, population-based survey, generic substitution, opinion, experience

\section{Introduction}

In many countries, generic substitution of an equivalent medicine (named also "generic drug") for a branded medication has been in place for more than a decade: in some countries successfully (such as USA, Sweden, UK, the Netherlands and Germany), and in other countries such as Portugal, Spain, Greece and Italy, with a modest degree of acceptance. ${ }^{1}$ In particular, Italy has the lowest level of generic market share volume in Europe $(<20 \%)$, immediately behind Portugal and Spain. ${ }^{1-6}$

In Europe, and especially in Northern European countries, the introduction of generic drugs (GDs) took place between the 1970s and 1980s. Italy is one of the European countries that has only recently clarified the concept of GD. The first complete and comprehensive definition was introduced in 1996 with the law n. 425/1996. According to the Leg. Decree 219/2006 (implementing 2001/83/CE directive), the term GD refers either to drugs that have lost the patent (off-patent equivalent drugs), are characterized by a fancy name (branded generics), are "pure" generics identified by the 
international non-proprietary name of the active ingredient followed by the name of the marketing authorization holder (unbranded generics), are a bioequivalent to a medicinal product already authorized with the same qualitative and quantitative composition of active ingredients, the same pharmaceutical form, and the same therapeutic indications. According to the laws $27 / 2012$ and $135 / 2012$, the physician is required to inform the patient of the existence on the market of a GD and to note only the name of the active ingredient in the National Health Service (NHS) prescription. Simoens et al have provided a comprehensive review on the current regulatory framework in Italy. ${ }^{\text {. }}$

Although the Italian policy of GDs promotion, by the physicians and pharmacists, is widespread, national data continue to highlight the limited success of GDs in Italy. ${ }^{4,6-9}$

\section{Aims of the study}

The purpose of this study is to investigate how the knowledge and use of GDs relate to socio-demographic variables and the approval rating of outpatients interviewed in Genoa, the regional capital of Liguria a Northern Italian region. Liguria was chosen for this study due to the fact that this Italian region appears to lag behind Northern Italy. National data on the percentage of GDs reimbursed by the NHS show that out of the total GD refunds, the Liguria region is slightly above (31.2\%) the national average $(28.4 \%$; range $18.3 \%-44.3 \%) ., 6,9$

A secondary aim was to assess general practitioner prescriptions of GDs in the class of proton pump inhibitors (PPIs), which are widely used in Italy and are often taken outside the prescribing guidelines. In fact, according to the National Report of the Italian Medicines Agency (AIFA) on the use of drugs in the general population, PPIs rank among the top in terms of prescription and expenditure reimbursement by the NHS. ${ }^{8,10}$

\section{Methods}

\section{Study population and design}

This is a descriptive, cross-sectional population survey study. The study was authorized by the Ethics Committee of the Liguria region in Genoa. All subjects were invited to participate and the study was verbally explained. Informed consent of both patients and general practitioners (GPs) was acquired. Interviews with outpatients and GPs were carried out in total anonymity to protect personal privacy. The questionnaires were directly and verbally administered by a single physician interviewer/investigator with formal training in medicine, between March and October 2014.

The city of Genoa has about 585,000 inhabitants and 525 GPs; $70 \%$ of GPs work in groups of 3-9, out of the same medical office. Every GP has a legal limit of 1,500 outpatients. For the purposes of our analysis, the city of Genoa was divided into 3 areas (east, west and center) with more or less equivalent numbers of inhabitants. These areas reflect the different socio-economic realities and demographic characteristics of citizens. The interviews took place at the 8 headquarters of the main outpatient clinics of the individual surveyed areas of the city (Figure 1). The study was divided into 2 separate surveys. The first survey was conducted by administering a questionnaire to patients. Interviews were held in a private room of the clinic, during regular opening hours while patients were waiting for their appointment. Interviews were conducted both in the morning and afternoon, to reduce differences in access across age and occupation classes. It is widely assumed that there is no difference between generic or equivalent, in-patent drug, off-patent drug, branded or unbranded GDs; therefore, we deliberately did not explain these differences to the population surveyed so as not to influence their opinions.

At the end of the interview, patients were allowed to ask for clarification on the survey or to express their views more freely to the same interviewer. As previously reported, ${ }^{11-13}$ this method minimizes the bias due to differences in subjective interpretation during data collection.

With regard to the second survey, once the first survey was completed, a questionnaire was administered to the 18 GPs, working in the same outpatient clinics as the previous survey in order to have a more complete picture of the use of GDs, assuming that GP preferences and medical advice influence patient use. This interview was also conducted in

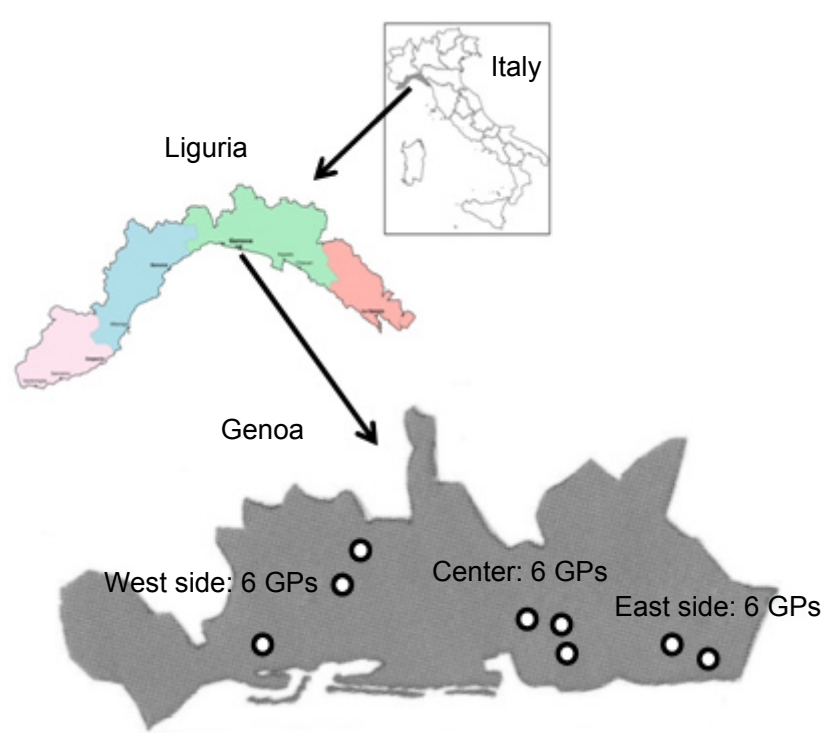

Figure I Maps, districts of Genoa and headquarters of outpatient clinics involved in the survey.

Abbreviation: GPs, general practitioners. 
anonymity and privacy, and GPs participated voluntarily at the beginning or end of their shift. GPs were unaware of the results of the first survey.

\section{Questionnaires}

Two structured questionnaires were prepared: one for the patients and another for the GPs. Previous research results were taken into account when assembling the questionnaires. ${ }^{11,13,14}$ All the questions were multiple choice and respondents could either choose an answer from between 5 and 8 options or simply answer in the affirmative or negative. The degree to which the patient questionnaire was comprehensible for participants was tested in an initial pilot survey of 180 patients attending a single outpatient clinic; the questionnaire has not been validated.

The patient questionnaire (Figures S1 and S2) was addressed to subjects of both genders, aged above 18 years, stratified into 3 age categories $(18-35,36-64, \geq 65)$, and according to their level of education and type of employment. The questionnaire consisted of 2 parts: the first part included 4 statements to assess kinds of respondents (Figure S1, questions from 1/A to 4/A). The second part (Figure S2) included questions to assess patient knowledge (questions from $1 / \mathrm{B}$ to 6/B) about generics and their use (questions 7/B and 8/B).

Respondents were asked if they had ever heard about GDs and, if yes, from whom (questions 1/B and 2/B); their approval rating and experience of drug substitution (question 4/B); if their physician had ever recommended the substitution of a branded medicine with a generic one thus saving money (question 3/B) or the possibility of substitution at the pharmacy (questions 6/B); the fifth question (question 5/B) was related to the assessment of their knowledge of the non-substitutability of GD. Experience with generics, motives for use and reasons behind their choice to use or not to use generics were assessed through the questions $7 / B$. Finally, the last question (8/B) assessed whether any side effects were observed when taking a GD.

For the second part of the study, a questionnaire (Figure S3) was administered by the researcher to GPs treating the same patients interviewed with the previous questionnaire. The structured questionnaire had 5 questions with a choice between at least 2 answers. Questions were related to the experiences, opinions and preferences in the area of PPIs prescription.

\section{Statistical methods}

The descriptive statistics used were mainly absolute number and relative frequencies (\%). Fisher exact (in case of $2 \times 2$ comparisons or when expected numbers were $<10$ ) or chi-square $(2 \times n$, with $n>2)$ tests were adopted to test differences between subjects who were aware or unaware of GDs, and between users and non-users.

Multivariate logistic regression analysis was adopted to estimate and test (using the Wald test) the strength of the association in terms of odds ratio (OR) between GD awareness/use and all the main demographic and social characteristics.

All analyses were conducted using STATA (version 13, StataCorp., College Station, TX, USA) software and the graphs were obtained with $\mathrm{R}$ (version 3.2.0). Two-tailed probabilities were reported and a $P$-value of 0.05 was used to define nominal statistical significance.

\section{Results}

A total of 2,134 patients were asked to participate; of these, $134(6.2 \%$, range $6 \%-18 \%$ for each of the involved districts) refused and 2,000 responded to the questionnaire.

\section{Respondents and knowledge of GD}

Among the 2,000 patients interviewed, 1,896 (94.8\%) declared that they were informed about the existence of the GDs. The main characteristics of responders in terms of knowledge of GDs are depicted in Table 1. Subjects informed about GDs were mostly females (61.1\% compared with $45.2 \%$ among those uninformed), aged over 36 years old (93.6\% vs $84.6 \%)$, with a high level of education $(51.4 \%$ had a high school diploma or university degree vs $21.2 \%$ ), and lived in the center-west side of the city (63.1\% vs 51\%). Office workers and professionals were significantly more represented among informed than uninformed subjects $(23.8 \%$ vs $13.5 \%$, respectively).

In the multivariate model (Figure 2), the factors that remain significantly associated with knowledge of GDs were being a female $(\mathrm{OR}=2.2 ; 95 \% \mathrm{CI}$ : 1.4-3.6), age $>36$ years old (middle aged and over 64 years old, OR $=7.0,95 \% \mathrm{CI}$ : 3.4-14.8 and OR =6.0, 95\% CI: 2.6-14.2, respectively, compared with the younger class), having an educational qualification higher than elementary school (secondary school OR =4.4, 95\% CI: 2.6-7.6; high school diploma $\mathrm{OR}=11.2,95 \% \mathrm{CI}: 5.6-22.5$; university degree $\mathrm{OR}=29.2$, 95\% CI: 8.1-106.0), and residence in the western side of city $(\mathrm{OR}=1.9,95 \% \mathrm{CI}: 1.1-3.5)$.

\section{Respondents and use of GD}

Among interviewees who knew GDs, only 1,115 patients ( $58.8 \%$ of 1,896 patients who know GDs) declared that they use them. The main characteristics of GD users are depicted in Table 2. 
Table I Main characteristics of subjects surveyed with respect to their knowledge of GDs, $n=2,000$

\begin{tabular}{|c|c|c|c|}
\hline \multirow[t]{4}{*}{ Variable(s) } & \multicolumn{2}{|c|}{ Knowledge of GDs } & \multirow[t]{4}{*}{$P$-value* } \\
\hline & \multirow{2}{*}{$\begin{array}{l}\text { No } \\
N=104\end{array}$} & \multirow{2}{*}{$\frac{\text { Yes }}{N=1,896}$} & \\
\hline & & & \\
\hline & n (\%) & n (\%) & \\
\hline \multicolumn{3}{|l|}{ Gender } & 0.001 \\
\hline Male & $57(54.8)$ & 738 (38.9) & \\
\hline Female & $47(45.2)$ & $\mathrm{I}, 158(6 \mathrm{I} . \mathrm{I})$ & \\
\hline \multicolumn{3}{|l|}{ Age (years) } & $<0.00 \mathrm{I}^{* *}$ \\
\hline $18-35$ & $16(15.4)$ & $122(6.4)$ & \\
\hline $36-64$ & $20(19.2)$ & $785(4 \mid .4)$ & \\
\hline $65+$ & $68(65.4)$ & $989(52.2)$ & \\
\hline \multicolumn{3}{|l|}{ Education } & $<0.00 I^{* *}$ \\
\hline Elementary school & $47(45.2)$ & $324(17.1)$ & \\
\hline Middle school & $27(26.0)$ & $576(30.4)$ & \\
\hline High school diploma & $19(18.3)$ & $731(38.6)$ & \\
\hline University degree & $3(2.9)$ & $242(12.8)$ & \\
\hline No title & $8(7.7)$ & $23(1.2)$ & \\
\hline \multicolumn{3}{|l|}{ Occupation } & $0.04 * *$ \\
\hline Laborers & $6(5.8)$ & $91(4.8)$ & \\
\hline Office workers & II (I0.6) & $312(16.5)$ & \\
\hline Professionals & $3(2.9)$ & $138(7.3)$ & \\
\hline Craftsman & $\mathrm{I}(\mathrm{I} .0)$ & $13(0.7)$ & \\
\hline Students & $4(3.9)$ & $20(1.1)$ & \\
\hline Unemployed and retired & $59(56.7)$ & $908(47.9)$ & \\
\hline Housewives & $20(19.2)$ & $4 \mid 4(2 \mid .8)$ & \\
\hline \multicolumn{3}{|l|}{ Side of Genoa } & $0.02 * *$ \\
\hline East & $5 I(49.0)$ & $699(36.9)$ & \\
\hline Center & $26(25.0)$ & $474(25.0)$ & \\
\hline West & $27(26.0)$ & $723(38.1)$ & \\
\hline \multicolumn{4}{|c|}{$\begin{array}{l}\text { Notes: Data are presented as absolute number (percentage); *Pearson's chi-squared } \\
\text { or Fisher exact test; **contrasts: age classes are all significantly different from each } \\
\text { other; education: the only non-significant difference is between university degree } \\
\text { and high school diploma; occupation: significant differences are between student } \\
\text { and anyone of the others except craftsman, and between unemployed/retired and } \\
\text { professionals; side of Genoa: the significant difference is between east and west. } \\
\text { Abbreviation: GDs, generic drugs. }\end{array}$} \\
\hline
\end{tabular}

Females were equally distributed between users and nonusers $(60.3 \%$ vs $62.2 \%$, respectively), while users were younger ( $\leq 65$ years old) than nonusers $(54.0 \%$ vs $38.9 \%)$ and had a high level of education $(57.2 \%$ had a high school diploma or university degree vs $42.9 \%$ ). GD users were more informed by mass media (19.0\% vs $15.1 \%)$ and more aware of the lower cost of GDs (79.4\% compared with $70.8 \%$ among nonusers). Moreover, among nonusers, the majority had parents or friends who did not believe in their efficacy (68.6\% compared with $44.8 \%$ in users). No differences in the areas of residence in Genoa were detected between users and nonusers.

In the logistic regression model (Figure 3), the factors significantly associated with use of GDs were younger age compared with over 65 years $(18-35$ years, OR $=3.11$, 95\% CI: $1.87-5.19 ; 35-64$ years, OR $=1.90,1.43-2.52$ ), a high level of education (high school diploma/university degree vs no title/elementary/secondary school OR $=1.67,95 \% \mathrm{CI}$ : 1.34-2.08), and the lower cost of GDs compared with brandname drugs (OR $=1.59,95 \% \mathrm{CI}$ : $1.25-2.01)$; the only factor significantly associated with non-use of GDs was the mistrust of parents and friends (OR $=0.34,95 \% \mathrm{CI}$ : 0.27-0.41).

Analysis of individual responses to questions 7 and 8 , showed that the majority of users were confident about the equal effectiveness and quality of GDs compared with branded drugs; $38.3 \%$ of patients felt that GDs had the same efficacy as branded medicines; while $31.0 \%$ believed that they were less efficacious. Furthermore, $85.6 \%$ of them thought that GD use did not entail risks with respect to drug safety (Table 3).

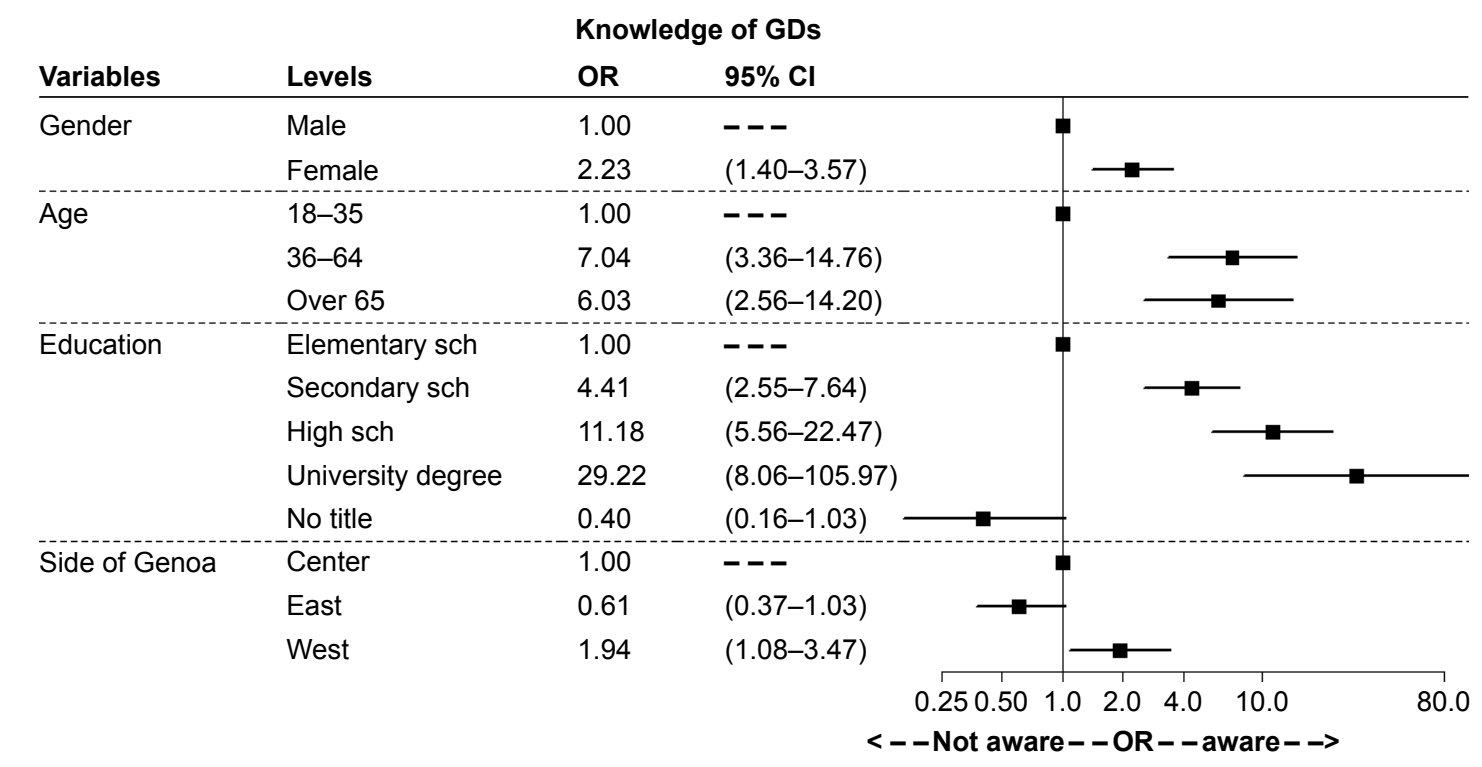

Figure 2 Odds ratio adjusted for gender, age, education, job and Genoa's geographical area. Abbreviation: GDs, generic drugs. 
Table 2 Main characteristics of subjects knowledgeable about GDs by use, $\mathrm{n}=\mathrm{I}, 896$

\begin{tabular}{|c|c|c|c|}
\hline \multirow[t]{4}{*}{ Variable(s) } & \multicolumn{2}{|c|}{ Use of GDs ${ }^{a}$} & \multirow[t]{4}{*}{$P$-value ${ }^{\mathrm{b}}$} \\
\hline & No & Yes & \\
\hline & $\mathbf{N}=78$ I & $\mathbf{N}=I, I I 5$ & \\
\hline & n (\%) & n (\%) & \\
\hline \multicolumn{3}{|l|}{ Gender } & 0.4 \\
\hline Male & $295(37.8)$ & $443(39.7)$ & \\
\hline Female & $486(62.2)$ & $672(60.3)$ & \\
\hline \multicolumn{3}{|l|}{ Age (years) } & $<0.00 I^{*}$ \\
\hline $18-35$ & $29(3.7)$ & $93(8.3)$ & \\
\hline $36-64$ & $275(35.2)$ & $510(45.7)$ & \\
\hline $65+$ & $477(61.1)$ & $512(45.9)$ & \\
\hline \multicolumn{3}{|l|}{ Education } & $<0.00 I^{*}$ \\
\hline Elementary school & $170(21.8)$ & $154(13.8)$ & \\
\hline Middle school & $268(34.3)$ & $308(27.6)$ & \\
\hline High school diploma & $240(30.7)$ & $491(44.0)$ & \\
\hline University degree & $95(12.2)$ & I47 (I3.2) & \\
\hline No title & $8(1.0)$ & $15(1.3)$ & \\
\hline \multicolumn{3}{|l|}{ Occupation } & $0.002 *$ \\
\hline Laborers & $21(2.7)$ & $70(6.3)$ & \\
\hline Office workers & $115(14.7)$ & $197(17.7)$ & \\
\hline Professionals & $63(8.1)$ & $75(6.7)$ & \\
\hline Craftsman & $6(0.8)$ & $7(0.6)$ & \\
\hline Students & $5(0.6)$ & $15(1.3)$ & \\
\hline Unemployed and retired & $384(49.2)$ & $524(47.0)$ & \\
\hline Housewives & $187(23.9)$ & $227(20.3)$ & \\
\hline \multicolumn{3}{|l|}{ Area of Genoa } & 0.4 \\
\hline East & $300(38.4)$ & $399(35.8)$ & \\
\hline Center & $186(23.8)$ & $288(25.8)$ & \\
\hline West & $295(37.8)$ & $428(38.4)$ & \\
\hline \multicolumn{3}{|c|}{ Source of information about GDs (Q.2/B) } & $0.003 *$ \\
\hline Doctors & $239(30.6)$ & $333(29.9)$ & \\
\hline Pharmacists & $336(43.0)$ & $489(43.9)$ & \\
\hline Mass media & $118(15.1)$ & $212(19.0)$ & \\
\hline People & $27(3.5)$ & $36(3.2)$ & \\
\hline Other & $61(7.8)$ & $45(4.0)$ & \\
\hline \multicolumn{3}{|c|}{ Knowledge about cheaper cost of GDs (Q.3/B) } & $<0.001$ \\
\hline No & $228(29.2)$ & $230(20.6)$ & \\
\hline Yes & $553(70.8)$ & $885(79.4)$ & \\
\hline \multicolumn{3}{|c|}{ Mistrust of parents and friends (Q.4/B) } & $<0.00 \mathrm{I}$ \\
\hline No & $245(31.4)$ & $615(55.2)$ & \\
\hline Yes & $536(68.6)$ & $500(44.8)$ & \\
\hline \multicolumn{3}{|c|}{$\begin{array}{l}\text { Knowledge about the notion of non-substitutability } \\
\text { (Q.5/B) }\end{array}$} & 0.01 \\
\hline No & $548(70.2)$ & $721(64.7)$ & \\
\hline Yes & $233(29.8)$ & $394(35.3)$ & \\
\hline \multicolumn{3}{|c|}{$\begin{array}{l}\text { The pharmacist proposed the change to GDs } \\
\text { (Q.6/B) }\end{array}$} & 0.1 \\
\hline No & $110(14.1)$ & $132(11.8)$ & \\
\hline Yes & $668(85.5)$ & $982(88.1)$ & \\
\hline
\end{tabular}

Notes: Data are presented as absolute number (percentage). ${ }^{\text {aN }}$ Number of users and nonusers was extrapolated from question Q.7/B, as the results of the sum of answers a-d (users), and the sum of the answers e-h (nonusers). 'Pearson's chisquared or Fisher exact test. *Contrasts: age classes are all significantly different from each other; education: significant differences are between elementary school and high school/Univ. Degree and between middle and high school; occupation: significant differences are between laborers and any of the other occupations except for craftsman and students; source of info about GDs: the significant difference is between the category "other" and doctors/pharmacists/ mass media.

Abbreviation: GDs, generic drugs.
All the 18 GPs surveyed answered the questionnaire. Due to the relatively low number of interviews carried out, the results cannot be statistically analyzed. Nonetheless, they showed that: $10(55.6 \%)$ GPs preferred to prescribe lansoprazole, 7 (38.9\%) used pantoprazole, and only 1 (5.6\%) used omeprazole. Fifteen (83.3\%) GPs stated that there was a justification for their preference, $2(11.1 \%)$ GPs asserted that it was a habit and only $1(5.6 \%)$ gave no particular reason. Ten (55.6\%) GPs expressed a preference for the originator over the generic, 8 (44.4\%) arbitrarily prescribed either branded or the GDs, and nobody specifically prescribed generics. All respondents (18/18) claimed to have found differences in the efficacy and/or tolerability of the GDs compared with the originator. Finally, the majority of respondents $(13 / 18$; $72.2 \%$ ) said that they discussed the differences in efficacy and tolerability between GDs and originators with colleagues and pharmacists (Table 4).

\section{Discussion}

The results of this survey showed that the degree of knowledge of generics in the sample examined is almost optimal, although there is an imbalance between the genders.

In our sample, of the subjects informed about GDs the most were 1) females; 2) over 36 years old; 3 ) had a high level of education; 4) office/professional workers; 5) living in the center-west side (poorest areas) of the city.

Therefore, young patients with a modest education who lived on the east side (the richest district) of Genoa, represented the groups that should be addressed to increase awareness of GDs.

In our study, GD users amounted to $58.8 \%$ of those who knew the GDs; in the logistic regression model, the main factor significantly associated with use of GDs was a younger age compared with over 65, there is an inverse relationship between knowledge and use of GDs. Moreover, the main users of GDs were patients with a high level of education and were mostly informed by mass media, pharmacists and physicians.

In our opinion the knowledge of drugs being greater in the elderly than in the young is not surprising considering that patients $>65$ years have a higher risk of morbidity and co-morbidity and usually take more medicines than younger people. Young people contact their GP less frequently than elderly patients; therefore, they do not become aware of developments in treatments (ie, the existence of GDs) and they certainly do not have years of experience with branded drugs like elderly patients with chronic conditions requiring extended treatment. Young subjects usually only use a drug for an acute disease for a short period of time. Therefore, it 


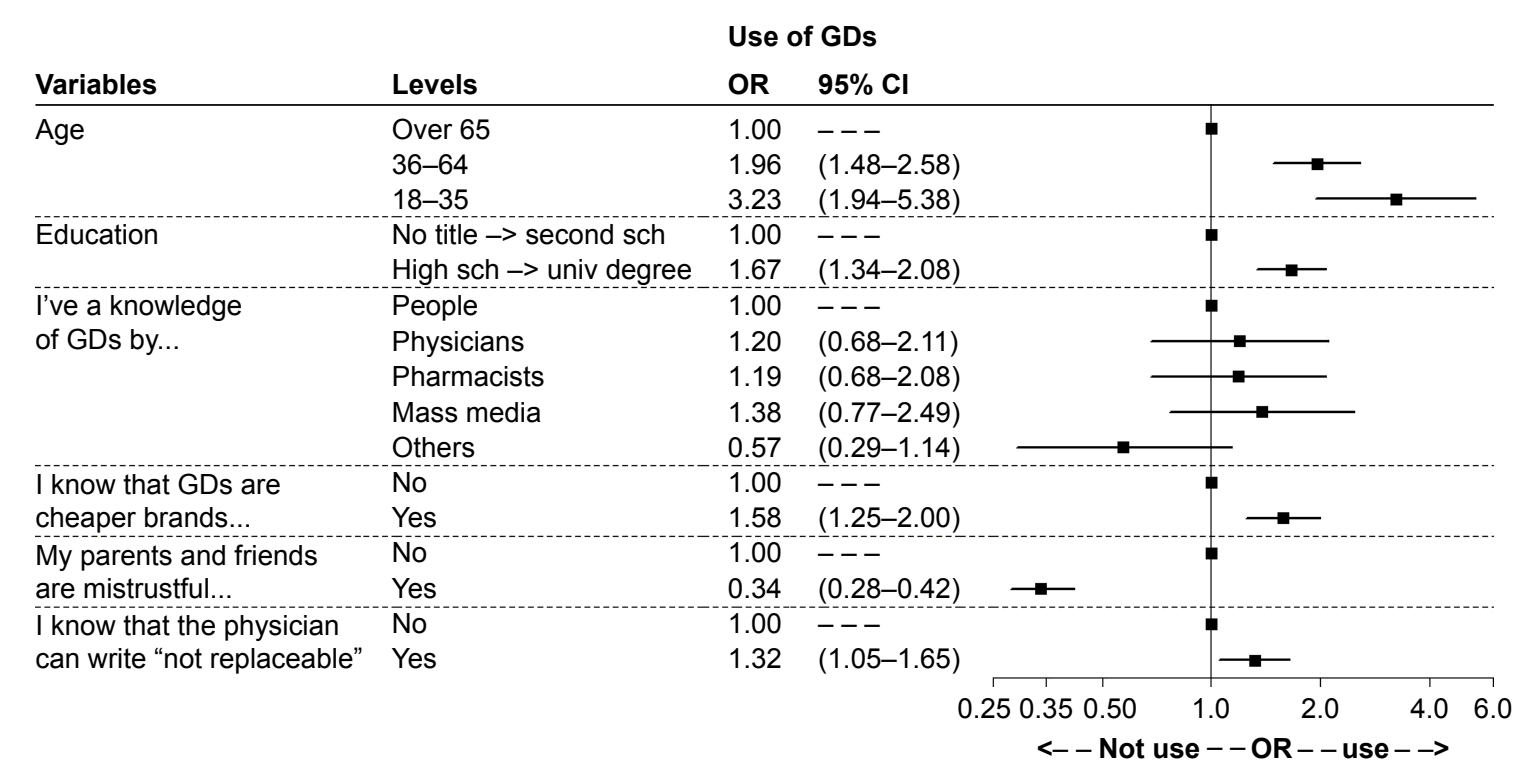

Figure 3 Odds ratio adjusted for gender, age, education, job, Genoa's geographical area, source of information about GDs, knowledge that GDs are cheaper brands, mistrust of parents and friends, knowledge of statement "not replaceable", pharmacist proposal.

Abbreviation: GDs, generic drugs.

is reasonable to assume that in terms of percentage, young people are more inclined to use a GD only when it is proposed by physicians/pharmacists or other sources of information (mass media). Patients $>65$ years were less likely to accept substitution than younger patients. Increasing age is associated with a less favorable attitude toward GDs, and patients rarely agreed to use the GDs for the treatment of a serious illness. ${ }^{15}$

Table 3 Answer to questions \#7, 8 (only to subjects knowledgeable of generics, $\mathrm{n}=\mathrm{I}, 896$ )

\begin{tabular}{ll}
\hline Have you ever used GDs (Q.7/B) & $\mathbf{n}(\%)$ \\
\hline $\begin{array}{l}\text { Yes, with the same efficacy and I saved money at the } \\
\text { same time }\end{array}$ & $727(38.3)$ \\
Yes, with less effects but I saved money & $66(3.5)$ \\
Yes, on recommendation by doctor/pharmacist & $277(I 4.6)$ \\
Yes, but I don't know the real reason & $45(2.4)$ \\
Total of users & $1,115(58.8)$ \\
No, I'm afraid it has less therapeutic effect & $587(31.0)$ \\
No, I'm afraid of adverse effects & $9(0.5)$ \\
No, I am not sufficiently informed about generics & $47(2.5)$ \\
No, I don't want to change & $138(7.3)$ \\
Total of nonusers & $78 I(4 I .2)$ \\
If you used GDs, did you experience any adverse & $\mathbf{n}(\%)$ \\
effects or diseases? (Q.8/B) & \\
Yes, so severe as to be hospitalized & $7(0.6)$ \\
Yes, I had to change therapy & $84(7.5)$ \\
Yes, I had to add other drugs to reduce adverse effects & $6 I(5.5)$ \\
Yes, but I did not report them to the doctor or & $9(0.8)$ \\
anyone else & \\
No & $954(85.6)$ \\
\hline
\end{tabular}

Note: *Percentage is on I, II5 users.

Abbreviation: GDs, generic drugs.
Similar considerations can be made for the degree of education; our data showed that knowledge and use of GDs were directly proportional to the degree of education, while other authors, such as Quintal et al, ${ }^{11}$ reported no significant differences in the use of GDs among levels of education but found a positive association with knowledge. This discrepancy could be attributed to the sample interviewed and to the site where the interview was conducted; Quintal et al conducted the interviews in a chemist shops where a heterogeneous population was represented, whereas our study

Table 4 Survey of PPI prescribing habits of general practitioners

\begin{tabular}{|c|c|c|}
\hline & $\mathbf{N}$ & $\%$ \\
\hline \multicolumn{3}{|c|}{ Active substance of the PPI class preferred (QI) } \\
\hline Lansoprazole & 10 & 55.6 \\
\hline Pantoprazole & 7 & 38.9 \\
\hline Omeprazole & 1 & 5.6 \\
\hline \multicolumn{3}{|c|}{ Is there a specific reason to prescribe a PPI? (Q2) } \\
\hline Yes, there is a reason & 15 & 83.3 \\
\hline No, it is a habit & 2 & II.I \\
\hline No particular reason & 1 & 5.6 \\
\hline \multicolumn{3}{|l|}{ Prescription habits (Q3) } \\
\hline No difference & 8 & 44.4 \\
\hline Prefer to prescribe branded medication & 10 & 55.6 \\
\hline Prescribe generics & 0 & - \\
\hline \multicolumn{3}{|c|}{$\begin{array}{l}\text { Difference in efficacy/tolerability compared with the } \\
\text { branded (Q4) }\end{array}$} \\
\hline Yes, sometimes & 18 & 100 \\
\hline \multicolumn{3}{|c|}{ Discussion of differences with colleagues and pharmacists (Q5) } \\
\hline Yes & 13 & 72.2 \\
\hline No & 5 & 27.8 \\
\hline
\end{tabular}

Abbreviation: PPIs, proton pump inhibitors. 
was conducted in outpatient clinics with a selected patient population. In our case, young GD-users knew that GDs were cheaper than originators and they went to the physician to obtain a prescription of a drug paid by the NHS. The Italian NHS is peculiar because all patients receive most drugs without paying and this certainly also influences the choice to use a GD. In fact, the universal health coverage system on which the Italian NHS is based ensures that price differences between GDs and originators are modest. While this may interest a patient with a low income, it will not influence the choice of an elderly patient with a chronic illness who prefers to continue using the originator drug, whose efficacy and tolerability he knows, rather than make a potential saving, prevalently for the State, by choosing the GD.

In the study by Maly et $\mathrm{al}^{16}$ conducted in the Czech Republic, 74\% of respondents believed in the full effect of GDs, while in another study conducted in Brazil, ${ }^{14} 74.8 \%$ believed that GDs were as effective as the branded drugs; in a Finnish study, Heikkila et $\mathrm{al}^{13}$ reported that about $80 \%-90 \%$ of respondents considered GDs and originators equally effective and thought that there were no differences in terms of quality, and only $16.3 \%$ of respondents rejected the replacement with an equivalent. Comparing these and our data, the results are quite different; the discrepancy between the studies could arise from the fact that the factor behind the decision to be a GD user is probably essentially a cultural factor in the sense that being aware of the existence of generics does not directly imply being well-informed about their efficacy and safety. There is scant scientific documentation on real-life clinical outcomes of substitution of treatment with GDs which has led to a sort of diffidence among Italian doctors and patients in relation to GD. Overall, our study's data seem in line with that of the Nomisma report, ${ }^{17}$ which highlights an unbalanced framework in which Italian patients are knowledgeable about generics $(90 \%)$ and $72 \%$ have used them in the last 12 months, but the market outcomes of GDs have not yet reached their full potential. There appears to be an "information vacuum" between doctors and GD producers, which leads to the use of "traditional" drugs, especially in cases of more serious illnesses. The main consequence of this is the need for more specific information about generics to be delivered correctly to all patients.

A positive result of our investigation is that $85.6 \%$ of GD users declared that they have experienced no more side effects than with branded drugs. However, $14.4 \%$ of patients who had used GDs declared that they had experienced more side effects than with branded drugs; this percentage is quite high and it is in clear contrast with the results of our second survey of the opinion of GPs on PPIs. In fact, all physicians surveyed still prefer to prescribe branded drugs instead of GDs, and they also declare that they have frequently found differences in efficacy and/or tolerability between GDs (generic PPIs) and originators. Although the limits of the second survey are obvious, and we are not able to give statistical meaning to the reported result, this seems to be an important sign of mistrust of GDs even among GPs themselves, which consequently affects their use by their own patients. These data appear in line with those of another study conducted in Saudi Arabia on physician opinions of GDs. ${ }^{18}$ This proves that a low level of knowledge among physicians about GDs might be a strong predictive factor for low prescription; therefore, increasing the knowledge among the GPs about the qualities and characteristics of GDs would lead to a promotion of their use. The European Generic and Biosimilar Medicines Association (EGA) study, ${ }^{5}$ states that "physicians need to be exposed to a higher quality of information from the responsible authorities to improve the rational prescribing", also through a strong intervention by governments. As reported by IMS Health study, ${ }^{2}$ in less developed GDs markets, such as Italy, the improvement of educational programs may be the best strategy to offer all the advantages of GDs rather than merely focus on price. Once again, Italian universal health coverage could be one of the reasons why GPs are no longer aware of GDs.

The main weakness of the present study is the lack of validation of the questionnaire. Moreover, it should be noted that this study was conducted in a single Italian city and it is important to underline that Liguria and, in particular, the city of Genoa, holds the highest Italian ageing index rate (ageing index in Liguria $=239.5 \%$ vs Italian mean $=151.4 \%$; ISTAT data $2014^{19}$ ); consequently, the largest number of respondents were over 65 years and only $6.4 \%$ patients were young. However, we believe in the importance of face-to-face interviews, rather than web-based or by telephone, with outpatients and their own physicians in order to provide new strategies to increase the knowledge/use of GDs. We think results from this study could be of interests to anyone who is interested in setting up a similar study, perhaps adopting validated tools and in a more extensive and comprehensive setting.

\section{Conclusion}

Despite a satisfactory knowledge of GDs in our region, data analysis shows that the degree of distrust is still very high and affects GD use; patients are still in doubt about GD efficacy. Unfortunately, the same degree of distrust is expressed by the GPs who are generally most concerned about potential 
changes in therapeutic effects, adverse effects and practical issues (eg, size, shape, and appearance) that may result from switching from branded to GDs. Patients should also be educated about the names of the active ingredients of their medicines to avoid confusion between different brands of the same medicine.

In the light of evidence on the advantages of GDs, both in money-saving terms and efficacy, promotion of these drugs is needed to assure both patients and GPs of their effectiveness and to combat the idea that cheaper products mean lower quality products, in terms of efficacy, safety and tolerability.

The previously formulated hypothesis, which associates scant use of GDs with the universal health coverage system, hampers appreciating the economic advantages of using GDs. Given that the low cost of GDs does not directly affect patients in Italy, in our opinion, information campaigns should be aimed at the economic advantages of GD use for the Italian state which, thanks to an increased use of GDs, would have more available economic resources to invest in innovative pharmaceuticals. An evident example of this are drugs for the treatment of the hepatitis $\mathrm{C}$ virus (HCV), which are only reimbursed to a limited number of patients selected on the basis of the seriousness of their hepatic illness. Thus, patients with low levels of liver impairment are excluded from reimbursement. Increased use of GDs would enable freeing up economic resources, which, in turn, could be used to extend the reimbursement of these drugs to all patients affected by HCV. We suggest directing an information campaign centered on the economic advantages of GDs to the associations of patients that often complain about the disparity of access to innovative drugs (in this example, innovative drugs that treat $\mathrm{HCV}$ ).

Finally, the limitations of our study notwithstanding, our results show that initial strategy to improve GDs knowledge should be targeted at young people, who require medical care less frequently and are therefore less informed by GPs or pharmacists.

It is more difficult to find an appropriate strategy for subjects with a low level of education or patients with higher economic status who have less need of GDs. Since results show that knowledge is directly proportional to the degree of education, an effective strategy should take advantage of the mass media as sources of information that rarely deal with this topic.

The trust of Italian patients in GDs is growing, ${ }^{17}$ but further improvement of information sources would allow younger patients to establish a trusting relationship with physicians. Health care professionals have an important role to play in helping patients understand that GDs are as safe and effective as originators. GDs manufacturers and distributors should work to fill this dearth of information by developing studies and exchanging information with physicians.

\section{Key points}

- Degree of distrust of GDs is very high and affects their use

- Women have twice the probability of having knowledge of a GDs compared with men

- Level of education is positively associated with knowledge of GD

- The main reason for using GDs instead of branded ones is the cost-effectiveness

- Subjects informed about GDs by the GPs have a higher probability of using them.

\section{Acknowledgments}

The authors would like to thank participating patients and GPs for their invaluable support in this study. The author would like to thank Dr Claire Marie O'Neil for her English language support. This work was supported by the Italian Medicines Agency-AIFA (FV-AIFA-GEN_2008-2009Ligurian Region Project).

The authors have not presented or posted this study or data anywhere and have solely submitted it to this journal.

\section{Disclosure}

The authors report no conflicts of interest in this work.

\section{References}

1. Dylst P, Simoens S. Does the market share of generic medicines influence the price level? a European analysis. Pharmacoeconomics. 2011;29(10):875-882.

2. IMS Health. A. Sheppard. Generic medicines: essential contributors to the long-term health of society. [monograph on the Internet]. Available from: http://www.imshealth.com. Accessed January 14, 2017.

3. IMS Health. Murray Aitken. The Role of Generic Medicines in Sustaining Healthcare Systems: A European Perspective, June 2015. [monograph on the Internet]. Available from: http://www.imshealth.com. Accessed January 03, 2017.

4. Assogenerici. Associazione Nazionale Industrie Farmaci Generici, a Company adhering to Medicines for Europe. Available from: http:/www. assogenerici.org $/ 2011 /$ centrostudi 1 .asp? $\mathrm{s}=3 \& \mathrm{p}=1 \&$ modulo=europa. Accessed January 14, 2017.

5. Bongers F, Carradinha H. How to Increase Patient Access to Generic Medicines in European Healthcare Systems. [monograph on the Internet]. A Report by the EGA Health Economics Committee, July 2009. Available from: http://www.medicinesforeurope.com/wp-content/ uploads/2016/03/Market_Barriers_Report_FINAL_update_How_ to_Increase_Patient_Access_to_Generic_Medicines.pdf. Accessed February 07, 2017. 
6. OECD. The Organisation for Economic Co-operation and Development. Health at a Glance 2015 OECD INDICATORS. Available from: http:// www.oecd.org/italy/Health-at-a-Glance-2015-Key-Findings-ITALYIn-Italian.pdf. Accessed January 14, 2017.

7. Simoens S, Dylst P, Vulto A. Analysis of the Italian generic medicines retail market: recommendations to enhance long-term sustainability. Expert Rev Pharmacoecon Outcomes Res. 2015;15(1):33-42.

8. Agenzia Italiana del Farmaco. L'Uso dei farmaci in Italia. Rapporto Nazionale. OsMed-Year 2015. Available from: http://www.aifa.gov. it/sites/default/files/Rapporto_OsMed_2015_AIFA.pdf. Accessed January 03, 2017.

9. Assogenerici. Associazione Nazionale Industrie Farmaci Generici, a Company adhering to Medicines for Europe. Available from: http://www. assogenerici.org $/ 2011 /$ centrostudi2 .asp? $\mathrm{s}=3 \& \mathrm{p}=2 \&$ modulo=mercato. Accessed January 03, 2017.

10. Heidelbaugh JJ, Kim AH, Chang R, Walker PC. Overutilization of proton-pump inhibitors: what the clinician needs to know. Therap $A d v$ Gastroenterol. 2012;5(4):219-232.

11. Quintal C, Mendes P. Underuse of generic medicines in Portugal: an empirical study on the perceptions and attitudes of patients and pharmacists. Health Policy. 2012;104(1):61-68.

12. Dunne S, Shannon B, Dunne C, Cullen W. Patient perceptions of generic medicines: a mixed-methods study. Patient. 2014;7(2):177-185.
13. Heikkilä R, Mäntyselkä P, Hartikainen-Herranen K, Ahonen R Customers' and physicians' opinions of and experiences with generic substitution during the first year in Finland. Health Policy. 2007;82(3): 366-374.

14. Lira CA, Oliveira JN, Andrade M, Vancini-Campanharo CR, Vancini RL. Knowledge, perceptions and use of generic drugs: a cross sectional study. Einstein (Sao Paulo). 2014;12(3):267-273. Portuguese.

15. BPJ, special edition: Generics. Best Practice Journal, Issue SE Generics July 2009. Available from: http://www.bpac.org.nz/BPJ/2009/generics/ contents.aspx. Accessed October 22, 2016.

16. Maly J, Dosedel M, Kubena A, Vlcek J. Analysis of pharmacists' opinions, attitudes and experiences with generic drugs and generic substitution in the Czech Republic. Acta Pol Pharm. 2013;70(5):923-931.

17. Assogenerici. Associazione Nazionale Industrie Farmaci Generici. Nomisma Reports. The Generic Drugs system in Italy - Scenarios for sustainable growth. May 5, 2015. Available from: http://www. assogenerici.org. Accessed January 21, 2017.

18. Salhia HO, Ali A, Rezk NL, El Metwally A. Perception and attitude of physicians toward local generic medicines in Saudi Arabia: a questionnaire-based study. Saudi Pharm J. 2015;23(4):397-404.

19. ISTAT. The Italian National Institute of Statistics is a public research organisation. Ageing Index 2014. Available from: http://www.istat.it/ en/. Accessed October 21, 2016 


\section{Supplementary materials}

\section{Part A - Questions regarding the patient interviewed}
Q.1/A Gender:
A. Male
B. Female
Q.2/A Age:
A. $18-35$ years old
B. $36-64$ years old
C. 65 years old

Q.3/A Education level:

A. Elementary school

B. Middle school

C. High school diploma

D. University degree

E. None

Q.4/A Profession:
A. Laborer
B. Office worker
C. Professional
D. Craftsman
E. Student
F. Unemployed, underemployed, retired
G. Housewife

Figure SI Questionnaire I: Questionnaire survey of generic drugs use.

\section{Part B - Questions regarding the survey about equivalents/generic drugs}

Q.1/B Have you ever heard about generic drugs?
A. Yes
B. No

If no, the survey ends here.

If yes, go to question 2/B.

Q.2/B From whom did you hear about generic drugs?
A. General practitioner or other specialist;
B. Pharmacist;
C. Mass media (TV, radio, web, newspapers);
D. Relatives, colleagues, friends, acquaintances;
E. Other

Q.3/B When your family doctor prescribes a drug, does he inform you that you can choose generic drug/equivalent drugs in lieu of brand-name drugs, thus saving money?
A. Yes
B. No

Q.4/B Among your friends, relatives and acquaintances, have you noticed any skepticism or distrust vis-à-vis generic drugs?
A. Yes
B. No

Q.5/B Did you know that your doctor can write "do not replace" on a prescription if he considers the assumption of that brand-name drug, rather than a generic one, important?
A. Yes
B. No

Q.6/B Has your pharmacist ever proposed substituting a brand-name drug with another equivalent/generic drug?

$$
\text { A. Yes B. No }
$$

Q.7/B Have you ever used equivalent/generic drug drugs?

A. Yes, because I think that the generic drugs have the same therapeutic effects of the original drug and I save money

B. Yes, because I save money, so I accept the lesser therapeutic effects

C. Yes, because my doctor or pharmacist recommended them

D. Yes, but I don't know why

E. No, I'm afraid they will have lesser therapeutic effect than original brand-name drugs

F. No, I'm afraid they will cause major adverse effects

Figure S2 (Continued) 
G. no, I'm not very knowledgeable about this topic and therefore I would need more reassurance and/or explanations before trying an equivalent instead of the original brand-name drug

$\mathrm{H}$. no, I am not very knowledgeable about this topic, and even if I were, I would not substitute the original drug

Answer the next question only if you have used generic drugs:

Q.8/B Have you ever had side effects or disorders when using generic/equivalent drugs instead of the original?

A. Yes, so severe as to be hospitalized

B. Yes, I had to go to the doctor who substituted the drug therapy

C. Yes, I had to go to the doctor who added other drugs to the existing therapy to better control the disease and reduce adverse effects

D. Yes, but I did not tell my doctor or anyone else

E. No

Figure S2 Questionnaire I: Questionnaire survey of generic drugs use.

Q1 - Tick the active substance of the PPI class that you usually prefer to prescribe:

Omeprazole (); lansoprazole (); pantoprazole (); esomeprazole (); rabeprazole (); I have no particular preferences, and agree to any specific patient requests ().

Q2 - If you have a preference in prescribing a PPI, is there a specific reason or is it based on your habits?

Yes, there is a reason (); No there is no particular reason, it's a habit ().

Q3 - Do you prescribe medication without specifying the "no substitution" or do you think that it is unimportant whether patients use original or generic drugs?

It makes no difference whether patients use original or generic drugs ();

I prefer to prescribe brand-name, rather than generic medication ();

I specifically prescribe generic medication ().

Q4 - When you prescribed generic PPIs, or when a patient received a generic PPI from the pharmacist, have you ever found any difference in efficacy or tolerability compared to brand-name drugs?

No, never (); Yes, sometimes (); Only with a particular type of generic medication ().

Q5 - If you found differences in efficacy and tolerability in a generic drug compared with the original medicine, did you report it or talk about it with colleagues or pharmacists?

Yes (); No ().

Figure S3 Questionnaire 2: Survey of PPI prescribing habits of general practitioners.

Patient Preference and Adherence

\section{Publish your work in this journal}

Patient Preference and Adherence is an international, peer-reviewed, open access journal that focuses on the growing importance of patient preference and adherence throughout the therapeutic continuum. Patient satisfaction, acceptability, quality of life, compliance, persistence and their role in developing new therapeutic modalities and compounds to optimize
Dovepress

clinical outcomes for existing disease states are major areas of interest for the journal. This journal has been accepted for indexing on PubMed Central. The manuscript management system is completely online and includes a very quick and fair peer-review system, which is all easy to use. Visit http://www. dovepress.com/testimonials.php to read real quotes from published authors.

\footnotetext{
Submit your manuscript here: http://www.dovepress.com/patient-preference-and-adherence-journal
} 